\title{
LA DIMENSIÓN ANAMNÉTICA DE LA FE: UN DIÁLOGO ENTRE MEMORIA HISTÓRICA Y ESCATOLOGÍA DESPUÉS DE LA SEGUNDA GUERRA MUNDIAL
}

\author{
The anamnetic dimension of Faith: a dialogue between historical memory \\ and eschatology after the Second World War
}

\author{
Carlos Alonso Gándara Ricardo ${ }^{\mathrm{I}}$
}

\section{Resumen}

El objetivo de este artículo fue iniciar un diálogo entre historia y escatología desde la experiencia del sufrimiento humano en Dios. Por tanto, se abordará el método dialéctico para establecer una reflexión hermenéutica que permita comprender el sufrimiento del presente desde la fuerza del pretérito y el compromiso con el futuro. Para ello, será fundamental el pensamiento teológico de Johann Baptist Metz y de otros autores, quien desde su propuesta teológico-política y desde la memoria provocadora en el contexto de un mundo altamente globalizado reivindica el problema de la teodicea desde la experiencia del hombre que sufre y reclama a Dios el fin inminente de este. Ahora bien, dentro del mundo académico de la teología, se han realizado varios esfuerzos por estructurar una teología política que mire al mundo, pues la fe cristiana es fe con los ojos abiertos, pero no ha obtenido la recepción necesaria dentro del mundo académico ni en el marco eclesial formal. Los esfuerzos realizados después del auge del Concilio Vaticano II despertaron en 1968 un clamor del oprimido, del pobre y del sufriente, que aún se desconoce tanto en el ámbito latinoamericano como en el europeo. En consecuencia, nace este

1 Licenciado en Teología por la Pontificia Universidad Javeriana Bogotá. Correo electrónico: cgandara@javeriana.edu.co. 
diálogo entre historia y escatología, en el cual se abordará, primero, la singularidad de la fe en la esfera de un nuevo nominalismo; segundo, la secularización del fruto del hombre burgués ilustrado y la modernidad, y, finalmente, se esbozará concretamente la relación entre memoria y esperanza en el contexto de Auschwitz.

\section{Palabras clave:}

Memoria; Fe; Sufrimiento; Política; Historia; Dialéctica; Hermenéutica; Conversión; Futuro; Escatología.

\section{Abstract}

The objective of this article was to initiate a dialogue between history and eschatology from the experience of human suffering in God. Therefore, the dialectical method will be addressed in order to establish a hermeneutical reflection that allows understanding the suffering of the present from the force of the past and the commitment to the future. For this, the theological thought of Johann Baptist Metz and other authors will be fundamental, as, from the author's theological-political proposal and from the provocative memory in the context of a highly globalized world, he vindicates the problem of theodicy from the experience of man who suffers and claims to God its imminent end. Now, within the academic world of theology, several efforts have been made to structure a political theology that looks at the world, since the Christian faith is faith with open eyes, but it has not obtained the necessary reception within the academic world or in the formal ecclesial context. The efforts made after the rise of the Second Vatican Council aroused in 1968 a cry from the oppressed, the poor and the suffering, which is still unknown in both the Latin American and European contexts. Consequently, this dialogue between history and eschatology is born, in which the singularity of faith will be addressed, first, in the context of a new nominalism; second, the secularization of the fruit of the enlightened bourgeois man and modernity, and, finally, the relationship between memory and hope will be concretely outlined in the context of Auschwitz.

\section{Keywords:}

Memory; Faith; Suffering; Politics; History; Dialectics; Hermeneutics; Conversion; Future; Eschatology.

\section{Es tiempo de que llegue el tiempo, es tiempo.}

Paul Celan

\section{Introducción}

Cada día que transcurre en la experiencia de la temporalidad se revelan más los grandes problemas a los que se enfrenta el hombre de hoy. Se hacen más evidentes los conflictos a los que el hombre, heredero de un largo entramado histórico, tiene que afrontar: migración, explotación de los recursos, censuras 
arbitrarias, concentración de la riqueza, mercantilización y tecnocratización ${ }^{2}$ de la vida, caótico mundo de la información, latente amenaza a la identidad de los pueblos dada por una desbocada globalización, manipulación genética, etc.

Frente a esto, la teología debe mirar a la historia cara a cara, desde todos los ángulos y observando todos sus matices. Una mirada y praxis teológica basada en el recuerdo del sufrimiento humano y no desde una indiferencia o desde un cinismo nietzscheano para poder encaminar un nuevo quehacer teológico y, por qué no, un nuevo concepto de remembranza o razón anamnética que posibilite nuevos horizontes de sentido en la experiencia humana.

Una "nueva mirada y praxisteológica que pueda inspirar a su vez una nueva forma de solidaridad, de responsabilidad para con los más lejanos, pues la historia del sufrimiento une a todos los hombres como en una segunda naturaleza" (Metz, 1979, p. 116).

De este modo, quisiera evocar la conocida metáfora del ángel de la historia, en la que se narra a un ser alado pasmado y petrificado por todo lo que observan sus ojos al mirar al pasado. Unas ruinas y un huracán que hasta ahora han escrito la historia de la humanidad:

Hay un cuadro de Klee llamado Angelus Novus. En él se representa a un ángel que parecería estar a punto de alejarse de algo que lo aterroriza. Sus ojos y su boca están abiertos de forma exagerada y sus alas extendidas. Este debe ser el aspecto del ángel de la historia. Es el ángel que ha vuelto el rostro hacia el pasado. Donde a nosotros se nos aparece una cadena de acontecimientos, él ve una única catástrofe que constantemente amontona ruinas sobre ruinas, arrojándolas a sus pies. Este ángel querría detenerse, despertar a los muertos y reunir lo destrozado, pero desde el paraíso sopla un huracán que, como se envuelve en sus alas, no le dejará plegarlas otra vez. Esta tempestad arrastra al ángel irresistiblemente hacia el futuro que le da la espalda, mientras el cúmulo de ruinas crece ante él de la tierra hasta el cielo. Este huracán es lo que nosotros llamamos progreso. (Benjamin, 2009, p. 140)

Desde la fe cristiana se reconoce que en la historia el hombre asume el acontecimiento del dolor; la historia ha sido historia de sufrimiento. Empero, si se habla de historia de sufrimiento, es necesario hablar y conjurar también la historia de la salvación, esto es, una historia con memoria. Nuestro mundo, cada vez más tecnocrático y globalizado, corre el peligro de perder la memoria con facilidad, en lo que sería un alzhéimer generalizado. La fe cristiana no mira hacia el pasado impotente como lo hace el ángel de Klee, ${ }^{3}$ sino que se presenta dialécticamente y prohíbe olvidar. La teología no concibe la historia como una "bella durmiente", y es ahí donde se ve limitada la labor de algunos historiadores y científicos sociales cuando estudian los hechos del pasado y los distintos fenómenos sociales del presente, y evalúan la realidad desde la "causa" y la "consecuencia", porque "el trabajo del investigador consiste en identificar, observar y explicar estos efectos” (Winner, 1987, p. 26).

2 Por ejemplo, Winner (1987) ofrece una respuesta frente a la búsqueda de los límites de la tecnología científica desde la reflexión filosófica.

3 Este pintor alemán nacido en Suiza fue uno de los más influyentes artistas del siglo XX. La técnica que empleaba en sus obras se basaba en el expresionismo, surrealismo, arte abstracto y arte moderno. No es de extrañar que el mismísimo Walter Benjamin empleara su obra como una analogía para representar su tesis sobre la historia (Correa, 2011). 
La teología se pregunta por el sentido de la remembranza y, con ello, se abre a la pregunta que la historia nunca deja de formularse, a saber: ¿por qué es posible el sufrimiento en el mundo?, porque "todo tiene un pasado que, en principio, puede reconstruirse y relacionarse con el resto del pasado"(Haldane, 1951, p. 79). El teólogo, ante todo, es un hombre afectado y herido por el sufrimiento,el propio, pero, en especial, por el ajeno. De este modo,

Para un cristiano que entiende su pasión por Dios como una "com-pasión”, como expresiónen absoluto afectada de un amor que se sabe enraizado en la indisoluble unidad del amor deDios y el amor al prójimo, para ese cristianismo, como digo, la historia de la humanidad (en el sentido de un macro-relato) cobra la forma de una historia de la pasión que se resiste tanto a la noción ("moderna") de una historia no dialéctica de progreso como al propósito ("posmoderno") de disolución de la historia en una inconexa pluralidad de historias. De ahí que el cristiano critique también una imagen pública de la historia que se sustrae en esencia a la dialéctica de memoria y olvido, contribuyendo así a estabilizar la amnesia cultural en laque la historia -en cuanto historia de la pasión- desaparece. (Metz, 2007, p. 17)

Por consiguiente, esta reflexión sobre el devenir anamnético de la fe no tiene per se como objetivo plantear un criterio de historicismo en lo que respecta a la fe en la historia, sino que más bien su finalidad estriba en la pregunta por el sentido de esa historia y la forma en que la fe ha enrumbado su constante devenir en medio del sufrimiento humano y lo ha acompañado, porque la historia no solo se concibe como una narración progresiva de acontecimientos, sino también como una estructura hermenéutica de participación. ${ }^{4}$

Con el método dialéctico y hermenéutico utilizado, queda superado el consabido problema entre la "historia desde arriba" y la "historia desde abajo", incluso la afamada nueva historia del gran Marc Bloch, tan fuertemente criticada por Burke; en realidad, es una apología de la historia de la esperanza (escatología), una nueva teodicea (si se me acepta la expresión). Y, por lo mismo, la historia se impone como una tarea previa: “qué sentido tiene el intento de investir de memoria el clamor de los seres humanos y de ponerle plazo a su duración?” (Metz, 2007, p. 1).

De este modo, la dialéctica ha de comprenderse situada en la realidad de la actual posmodernidad: la globalización y la pluralización del mundo. La fe en el recuerdo del acontecimiento de Jesús de Nazaret no se encuentra en un mundo temporal cerrado, sino en otras grandes realidades que exigen cada vez más un diálogo permanente, una tolerancia siempre en movimiento y una acción y razón discursivas cada vez más comprometidas con los límites, los desafíos y las diversidades a las que estamos expuestos todos los seres humanos.

El método dialéctico que me propongo, fundamentado en el saber teológico y la añoranza bíblica, no tiene como objetivo anular o desacreditar el mundo de la globalización y la pluralización, sino más

4 Al respecto, es necesario considerar lo que se puede inferir de la propuesta de Ellacuría (1973), a saber: el giro escatológico: "Por tanto, no es solo que la historia de la salvación traiga consigo una salvación en la historia: es además que la salvación del hombre en la historia es la única forma de que culmine la historia de la salvación (p. 10).

5 Historiador francés y fundador de la Escuela de los Annales, quien con su nuevo enfoque de la historia prescinde del individuo como agente protagonista y se enfoca en los procesos y estructuras sociales. 
bien erigir puentes de convergencias para minimizar los riesgos que supone el desconocimiento de otras realidades que suelen permanecer inconexas y generar grandes situaciones de violencia que hubieran podido evitarse con esfuerzos narrativos, dialógicos y discursivos.

El método dialéctico, de la mano de la teología de la anamnesis y la esperanza en Dios (escatología) no solo se funda en el examen crítico sobre la tesis hegemónicas de la historia, sino que también reconoce el mundo de la experiencia que se desarrolla en el espacio y en el tiempo, una historia vinculante, así lo pretende este artículo, entre recuerdo (añoranza) y creatividad (esperanza). El saber teológico añorante y esperanzador a la vez fortalece y retroalimenta el método diálectico, porque "la teología se basa en la suposición de que el ser humano no es solo un experimento de sí mismo (como desde Nietzsche gusta asumir la creciente medida del espíritu posmoderno), sino también -de forma más fundamental y con una permanente pretensión de normatividad-su propia memoria” (Metz, 2007, p. 161).

Este mundo de la fe, esta historia de sufrimiento, del que se quiere cerciorar y que se suele denominar mundo de acontecimientos, ${ }^{6}$ ya es de suyo un mundo dado; en cierto modo, un "antemundo", es decir, un mundo que en sí mismo ha mostrado su propia realidad y que está conformado por un entramado de acontecimientos o, como afirma Burke (1993), "de interacción entre acontecimientos" (p. 26). Y, en consecuencia, solo puede ser analizado y experimentado eventualmente dentro de la misma historia, pero no al modo de la filosofía de Wittgenstein, quien ha decidido "dejar todo tal como está" (Wittgenstein, 2016). Quien pierde de vista esto incurre fácilmente en un concepto acrítico de la historia misma. De este modo, un discurso de fe que no considere la complejidad histórica del mundo no pasa de ser un sermón piadoso, pero vacío e ineficaz, porque, como afirma el mismo Metz (2007), "estas reflexiones tienen como guía aquella dialéctica histórica que niega a la teología la posibilidad de servirse, una vez más, de una lógica intemporal de fundamentación y de los correspondientes conceptos ahistóricos y desprovistos de sujeto” (p. 1).

La escatología se opone a la historia de sufrimiento, a este mundo plagado de contingencias históricas, pero no lo hace para huir de la historia del hombre, antes bien, la escatología asume que la fe sobrepasa todas estas realidades, pero tampoco la ubica en un plano supracelestial o utópico, sino que la fe se dilata en espera o, como bien diría Kierkegaard (2001), en un "apasionamiento por lo posible". De este modo, se hace imprescindible el uso del método dialéctico, toda vez que la teología distingue el saber técnico del saber añorante, distinción que no solo responde a la cuestión directa sobre Dios sino también al hombre. El método diálectico de la mano de la teología nos abriría aún más en el mundo de la experiencia, para "mantenernos dispuestos a mirarnos y valoraros a nosotros mismos no solo con nuestros propios ojos, sino también con los del 'otro mundo', con los del 'resto del mundo', como tan dolorosamente se dice” (Metz, 2007, p. 170).

Todo sistema de interpretación general dentro del cual acontece la experiencia del mundo está enraizado históricamente. ${ }^{7}$ Cuando se habla, por ejemplo, de escolástica, Ilustración, civilización burguesa

6 Lo que intento expresar va en sintonía con lo que ya había afirmado Ricoeur (1995): "Lo que tiene que ser entendido no es la situación inicial del discurso, sino lo que apunta a un mundo posible [...] mostrar es una nueva forma de ser" (p. 100). Es decir que la historia, por más que sea dada en acontecimiento pretérito, este acontecimiento es también apertura hacia delante.

7 Toda interpretación es fundamental no solo cuando se habla del pasado, sino también del futuro. Pues, si el objetivo es saber más, entonces el saber nunca serán lo suficiente. De ahí que la base de la interpretación es siempre el interrogante, porque las preguntas abren el horizonte temporal. 
occidental, Revolución francesa o Revolución industrial, etc., se habla al mismo tiempo de una dialéctica de la historia; pero en lo que compete es necesario también integrar el sentido trascendente de esa historia de sufrimiento que es, ante todo, una historia de fe o, como afirma Agustín de Hipona (2011), "se actualiza el pasado para predecir el futuro". Por tanto, el objetivo de este artículo es plantear un diálogo entre historia y escatología, porque, de este modo,

el sentido de la historia, el interés por la historia y la necesidad en entender la historia surgen siempre en tiempos críticos, en tiempos inquietos, que emergen en el horizonte de posibilidades nuevas, no conocidas ni sospechadas hasta ahora. Para entender el nuevo presente y para poder vivir en él, es preciso trabajar sobre el pasado, bien para esclarecer una concordancia entre las nuevas experiencias y la tradición del pretérito, bien para quedar libres, para el nuevo presente, del peso del pasado. (Moltmann, 1972, p. 302)

En consecuencia, el esquema reflexivo a desarrollar quedará planteado del siguiente modo. Primero, se desarrollará el consabido problema de la formulación de los universales, ahora confrontados por el sufrimiento humano, que se ubica concretamente en una historia singular de sufrimiento. Segundo, se abordará el problema de la secularización iniciada por el hombre burgués frente al intento de emancipación de su autonomía respecto del Antiguo Régimen y sus posibles consecuencias teológicas en la fe anamnética y escatológica. Finalmente, se tratará el problema que implica hablar de Dios y "hacer teología" después de Auschwitz. La Segunda Guerra Mundial ha puesto en crisis la condición política y socioeconómica del hombre, asimismo, su experiencia vital de un futuro posible y un pasado que parece ya olvidado.

\section{Una historia de clamores: de lo universal a lo singular}

La contingencia humana evidenciada después de la Segunda Guerra Mundial no solo trastocó y modificó la dimensión política, ética y económica del hombre, sino también, y de manera quizá más radical a la teología, porque la realidad teológica representa el espíritu de la mediación entre lo singular y lo universal, lo particular y lo común. La metafísica ahora se ve afectada por la singularidad histórica del sufrimiento humano; es este mismo, la "categoría epistemológica" que vendría a poner en crisis todo el estamento racional constitutivo de la teología. Es en este sentido en el que la sabiduría bíblica deja una gran lección, tanto más cuanto que en ella se manifiesta esta singularidad de la experiencia del hombre desconocida muchas veces por la razón filosófica y la razón teológica.

La manera como la Biblia ha registrado la narración de la experiencia humana, de la condición de seres finitos lanzados a un espacio-tiempo infinito durante un periodo limitado, no se ha superado (¿̨o tal vez sea que, habiendo modelado nuestra experiencia durante milenios ha dispuesto el marco para todos los registros futuros?). El resto de metáforas palidece en comparación. Admito francamente que, en tanto que relato del paso de la nada al ser, encuentro el cuento del "Bing Bang" mucho más pobre que el relato de los seis días de trabajo de Dios. Y menos esclarecedor. La historia carece de personaje alguno que nos informe sobre si lo que había surgido de la "nada" prístina tras los primeros segundos era bueno o malo. (Bauman y Tester, 2002, p. 183) 
La crisis que supone el nominalismo se traduce en el reconocimiento de lo singular: la apertura de una nueva cosmovisión que asume una comprensión distinta y particular de la historia que ya nopuede ser explicada ni fundamentada por la clásica teoría de la metafísica universal. ¿Qué tan vigente se encuentra este nominalismo? ¿Qué cambios ha tenido desde el Edad Media hastanuestros días? ¿Qué nos podría decir hoy frente a la contingencia e insuficiencia humana? Sospecho que no pocas cosas.

El nominalismo teológico de Guillermo de Ockham no solo representa un radical cuestionamiento de la racionalidad humana a causa de la disolución de todas las constantes racionales bajo la presión de la arbitraria omnipotencia divina, sino la definición de dicha racionalidad, en concreto en cuanto experimento de determinación de la misma no ya desde lo universal abstracto, sino enteramente desde lo singular. (Metz, 2007, p. 55)

El problema entre lo universal y lo particular está relacionado con la experiencia de la "alteridad", lo que supone la formulación de universales, que trae consigo el desconocimiento del otro, porque, para la nociónuniversal de la realidad, el otro no tiene nombre, ni rostro, ni forma: ¿quién sufre?, ¿dónde sufre? y ¿por qué sufre? son preguntas que la noción universal pasa por alto, pero, además, no le interesa responder; el mismo Lévinas (1977) en tu tajante crítica afirma que el "Dasein de Heidegger no tiene hambre".

Esta singularidad no puede conducirnos a un desconocimiento de un proyecto auténticamente universal: nuestra historia es de todos. Una historia en la que el sufrimiento no ha quedado en el pasado, sino que es presente. ${ }^{8}$ Una historia que no es complemente ida y un sufriente que no es un anónimo pretérito. "Esto significa que el problema real que plantea la inclusión en el concepto de universalidad bíblico de las víctimas injustamente desaparecidas es el de la posibilidad de hacerles justicia en la historia" (Fraijó, 1994, p. 331).

El reconocimiento de la singularidad implica el reto de emprender una críticaa las certezas universales de la teología, una apertura sensible a la contingencia, una amplitudde la compasión en el devenir de la historia y la tarea siempre pendiente de la justicia, que no se supedita al hecho del pasado, porque, incluso, aunque fuere posible realizar la justicia conforme al hecho y al derecho, las posibilidades de sufrimiento seguirán siempre pendientes. "Nos encontramos así ante una situación aporética: reconocemos al hombre sus derechos pendientes, pero no vemos que haya instancia humana capaz de saldarlas" (Fraijó, 1994, p. 332). En consecuencia, para el cristianismo, la historia depende de Dios y, de este modo, se salvaguarda que la fe incurra en ideología.

Dicho de otro modo, el discurso sobre Dios después de la Segunda Guerra Mundial no puede seguir siendo pensado con categorías abstractas (Torres, 2005, p. 47). Esto fue lo que supuso el "segundo nominalismo" surgido a partir de la modernidad y su proceso de secularización; no se puede seguir

8 Lo que intento hacer es superar la dicotomía entre lo que le ocurre al individuo y lo que le sucede sujeto de la historia. El consabido conflicto entre autobiografía e historia objetiva. Es un poco lo que afirma Zamora (2008): "Todas las huellas están en el presente. Ninguna habla de ausencia, menos de una de anterioridad [...] La memoria a la que evoca el perdón no encadena al presente al pasado traumático. Es una memoria que recupera la perspectiva de la víctima para poder romper el poder del mal en el presente. El dolor del dańo, de lo que perdió quizá irrecuperablemente, bajo la perspectiva del perdón se convierte en motivación para construir un presente y un futuro liberados” (p. 72). 
pensando a Dios por encima de la historia concreta de la humanidad que ha sido historia de sufrimiento. Este compromiso nominalista le exige a la teología replantearse su método y sus razones, porque "no es en torno al discurso del 'Motor Inmóvil' de Aristóteles, sino sobre el Dios de Abraham, de Isaac y de Jacob" (Metz, 2007, p. 74).

Lo que se pretende no es una posición radical y anuladora de la metafísica y la ontología, sino una nueva hermenéutica que asuma la temporalidad singular del hombre que sufre, vivos y muertos por igual. Una metafísica que asuma los acontecimientos, pues el sufrimiento se extiende a todos los hombres, incluso a los muertos. Este replanteamiento es necesario porque la universalidad de la esperanza en la justicia no puede dejar de lado precisamente a las víctimas de la injusticia, porque, "si la historia se centra en los vivos, la historia será de los vencedores y se entenderá a los perdedores como el precio histórico para la felicidad de los presentes. Esos perdedores será la prehistoria, mientras que la historia será de los vencedores" (Freijó, 1994, p. 332).

El sujeto universal de la historia es al mismo tiempo un sujeto particular; su particularidad estriba en que es un sujeto que sufre, es el sujeto sufriente. De este modo, la teología está llamada a "acariciar los contornos del cuerpo del otro teniendo cuidado de no apretar demasiado, de no agarrar al acariciado demasiado firme e inconfortablemente, de no amenazar con deformar su silueta, masculina o femenina" (Bauman y Tester, 2002, p. 181).

El Reino de Dios se parece a una caricia porque esta nos salva del anonimato, nos redimedel olvido universal y eleva al hombre al rango de lo irrepetible. Pues bien, esta caricia de Dios hacia el hombre se llama Jesucristo. Este "nuevo nominalismo", en realidad, sefundamenta en la cristología del Unigénito. En efecto, la singularidad teológica pone de manifiesto la "kenosis" de Dios, su radical vaciamiento y su determinado anonadamiento en un solo hombre, que, aunque singular, es hombre entre todos los demás.

No ha de entenderse esta "kenosis" como una superficial vinculación de Dios con el hombre que mantendría el mismo misterio de la encarnación encerrado en círculos dualistas y alejados del hombre en concreto en tanto sujeto de la historia, porque Jesucristo es hombre y también "sujeto de la historia" "igual que sus hermanos en todo" (Heb 2, 17); en todo, "salvo en el pecado" (Heb 4, 15). Por consiguiente, "la elevación de Cristo sobre los restantes 'hermanos' y participantes en la naturaleza humana no puede interpretarse unilateralmente, de tal modo que ponga en peligro la irrepetibilidad y la unión en lo común, y que la analogía en lo concreto-histórico absorba la identidad en la esencia” (Von Balthasar, 1992, p. 14).

Esta singularidad de Jesús en relación con sus "hermanos" no ha de entenderse desde la ideade alteridad que plantea Lévinas cuando expresa que el yo y la alteridad, aunque están condenados a encontrarse, no son conmensurables, porque el otro es infinito, y en tanto infinito pertenece a la esencia inconmensurable de Dios y del futuro. Si aceptáramos esto sin más, la singularidad del Jesús histórico perdería toda su concreción real de hombre en mediode los hombres, con ellos y para ellos, y la vinculación con Él solo estaría asumida por analogía. Por tanto, la "kenosis” de Dios es la garantía de la singularidad de Jesús y la pluralidad de nuestra humanidad.

Así, aparece la solución para nuestro problema de salida entre lo concreto-histórico y lo abstractonecesario: 
Si uno de nosotros es entitativamente una misma cosacon la Palabra de Dios y la acción redentora de Dios, queda elevado por ello mismo, como tal individuo irrepetible, a norma de nuestra esencia, así como de nuestra historia concreta, la de todos los individuos y la del género. (Von Balthasar, 1992, p. 15)

\section{La modernidad y la crisis de la secularización del hombre ilustrado: crítica teológica}

La reflexión escatológica se ubica más allá de todo idealismo; es cierto que el cristianismo ha concebido dualmente la historia, porque, por un lado, ubicó la salvación individual, y por otro, determinó la historia en general, y por mucho tiempo la dividió entre profana y sagrada.

La escatología admite la integración histórica, esto es, la historia es una, porque ella es el topos en el queel hombre está radicalmente abocado a realizarse, a erigirse no solo como sujeto histórico, sino además, y sobre todo, como sujeto de la historia. Un topos en el que este sujeto se juega el destino de la salvación y en el que sin duda puede encontrar la privación y frustración a sus esperanzas.

Karl Löwith ha llamado al historiador profeta vuelto hacia el pasado. Podemos completar su punto de mira diciendo que el profeta es un historiador que mira al futuro. Si el historiador descubre esperanza en el modo del recuerdo, el profeta diseñarecuerdo en el modo de la esperanza. (Moltmann, 1987, p. 110)

La integralidad histórica aceptada por el cristianismo fue poco a poco disolviéndose en el tiempo. La Ilustración como movimiento de emancipación del sujeto libre y autónomo respecto de las fuerzas heterónomas que lo supeditaban significó, o al menos eso se pensó, su plena madurez:

La Ilustración es la salida del hombre de la minoría de edad, en que autoculpablemente se hallaba. Minoría de edad es la incapacidad de disponer del propio entendimiento sin la dirección de otro. Autoculpablemente, lo es esta minoría de edad porque su causa no radica en una carencia de entendimiento, sino en una carencia de decisión y coraje para disponer de uno mismo sin la dirección de otro. (Kant, 2004, p. 10)

Lo que sugiere Kant es la emancipación del sujeto. El resultado de este proceso de "modernización europea" condujo en realidad a lo contrario. Se esperó que pudiera guiar al hombre en su realidad y condición de ser humano, pero ocasionó el detrimento del reconocimiento de sus semejantes, la lejanía de una consciencia histórica; ytodo esto se traduce en la desespiritualización del hombre mismo o lo que se conoce como "secularización".

La modernidad misma solo es posible comprenderla bajo estos presupuestos, pero "la llamada 'secularización' de la era moderna no fue más que la designación de un vocabulario que pudiera ser utilizado para expresar la condición humanasin utilizar la palabra 'Dios'” (Bauman y Tester, 2002, p. 182). En efecto, la secularización no solo tiene el componente histórico del precedente de la constantinización del cristianismo (Bizancio, Roma, Reforma y Contrarreforma), o el contexto "de la miseria de las guerras de fe de los hugonotes en Francia [...]., que trató de solucionar el conflicto con edictos de tolerancia y con el derecho de la libertad religiosa” (Moltmann, 1987, p. 57). 
Lo que se pretende es interpretar teológicamente la categoría de "autonomía" tan profundamente arraiga cuando se habla de Ilustración, modernidad y secularización, de forma indistinta, pero que integra el "trípode". En consecuencia, "la secularización moderna designa en primer lugar el paso de contenidos teórico-prácticos e instituciones de carácter eclesiástico- religioso a otros de carácter laico-civil. Este paso puede significar emancipación (rechazo, negación o simplemente independencia) y transposición (trasladotraducción consciente o inconsciente)" (Amengual, 1990, p. 59).

Es lo que se conoce como la "mundanización del mundo" o lo que Max Weber llamaba de forma muy apropiada "el desencanto del mundo" (Weber, 1922 , p. 535), en que se pregunta, precisamente, con respecto a la ciencia y la técnica por el sentido de esta nueva racionalidad analítica del hombre heredero de la autonomía ilustrada. No es que se esté negando el valor de la autonomía del sujeto libre, pensante y racional, sino que el problema subyace bajo el sentido crítico de la promesa del hombre libre respecto de las fuerzasque siempre intentan alienarlo, máxime si este estandarte de la autonomía a la larga se ha convertido en una enajenación más.

¿Hasta qué punto puede reconocer la autonomía del hombre la responsabilidad por una historia de sufrimiento de la humanidad?? Y si no, ¿no es esta autonomía un matrimonio clandestino entre la metafísica y una libertad ahistórica? Es cierto que frente a estas preguntas el cristianismo, así como hoy la modernidad, no resultan indemnes. La misma reflexión de Agustín de Hipona (2011) contra Marción atribuye toda la responsabilidad del mal y del sufrimiento en el mundo al hombre, negando explícitamente cualquier interpelación de teodicea dirigida a Dios mismo como agente directo e implicado de la historia.

El Espíritu de la fe bíblica confronta a la modernidad para que esta asuma la historia no solo como movimiento progresivo o evolutivo, sino también en su más profunda singularidad: recordando al vencido, reparando lo destruido y encontrando lo perdido. La historia es una protesta contra el sufrimiento humano, porque "somos producto del pasado, y estamos viviendo sumergidos en el pasado, que por todas partes nos oprime. ¿Cómo emprender nueva vida, cómo crear nuestra acción sin salir del pasado, sin sobrepujarlo?, ¿y cómo sobrepujarlo, si estamos dentro de él y él estácon nosotros?” (Croce, 1960, p. 29).

En consecuencia, es cierto que a la modernidad con su gran movimiento humanista ilustrado le debemos la exigencia que impulsó el derecho humano individual de la expresión de la libertad religiosa y la libertad de consciencia. Frente a un Estado totalitario e impositivo, poco a poco fue ganando terreno una minoría relegada que se resistía a la homogeneización social y cultural; entonces, ocurre que el Estado se seculariza. La misma Iglesia como institución jerárquica y disciplinaria tuvo que adaptarse y acoger el respeto de la dignidad de la persona en la reafirmación de su libertad y pluralidad. Así las cosas, la modernidad no solo introdujo la desacralización del mundo, sino también la libertad religiosa, esto es, lo que caracteriza a la Europa moderna: el humanismo moderno. "Porque solo el desarrollo de los derechos humanos, convirtiéndolos en fundamento de la cultura y de la política, ha conseguido que las consecuencias destructoras de la división eclesial occidental pasen a tener un sentido positivo. De la división eclesial 'occidental' surgió la 'Europa' ilustrada, humanista” (Moltmann, 1987, p. 58).

9 "Esta pregunta denota la nuda angustia de vivir en su carácter de suerte" (Ricoeur, 2008, p. 54). 
El valor de dialogar y confrontar abiertamente la modernidad constituye una destacada característica de la teología después de la Primera y Segunda Guerra Mundial, porque, en toda teología y en especial en la escatología, palpita el saber añorante, la remembranza; una teología de cara al tiempo, una teología política; así como afirmaron los precursores de Tubinga, a saber: Hegel, Schelling y Hölderlin: está llegando el Reino de Dios, ¡que no descansen ociosas nuestras manos en el regazo (Kasper, 1974, p. 18).

Por otra parte, en 1886, Nietzsche afirma su apotegma más famoso: "Dios ha muerto"; pero, ¿cuál es la consecuencia histórica de esta afirmación?, ¿qué ocurre si "Dios ha muerto"?, y, aún más, ¿qué le ocurre al hombre?

En efecto, Nietzsche es por excelencia el "hijo de la modernidad", pero como todo hijo sigue su nuevo camino, a saber: la posmodernidad. Con Nietzsche, se inaugura el periodo contemporáneo, el surgimiento de la "deconstrucción", o lo que él llama "filosofar a martillazos". Pero ¿qué es lo que martilla propiamente? Al humanismo moderno, los ideales modernos, martilla las "Luces", a Descartes, a Kant, a Voltaire, al cristianismo. ¿La consecuencia? "Donde no existe Dios, el olvido se convierte en la única condición de la felicidad humana. Nietzsche vincula su "nuevo estilo de vida" a una cultura del olvido, a la amnesia cultural que cada vez caracteriza en mayor medida nuestro paisaje posmoderno (Metz, 2007, p. 82).

¿Cómo responder al "martillazo"? ¿Cómo negarnos al olvido? Con solidaridad anamnética, con evocación, con provocación, con una apología de la historia de los vencidos, no para que se conviertan en vencedores y así seguir dando continuidad a la "monstruosa rueda de la historia", sino para no incurrir en lo que ya había identificado Adorno (1974) en su crítica a la burguesía: "En el tipo burgués no ocurre que a partir de los momentos de gozo la felicidad irradie a toda la vida e ilumine también aquellos sectores que no son alegres en sí mismos" (p. 161).

\section{Memoria y conversión: la fe y la historia después de la Segunda Guerra Mundial}

Las expresiones "sufrimiento", "teología del sufrimiento", "sufrimiento en Dios" o "historia del sufrimiento en Dios" no han de entenderse solo como categorías epistemológicas o reducciones categoriales teológicamente hablando. Estas expresiones han de comprenderse desde la fuerza de la evocación que surge del mismo sufrimiento humano que no es querido por Dios, ni provocado por Él, sino que es "sufrimiento en Dios". De este modo, la modernidad vino a representar ese límite de la contingencia humana, la radical vaciedad de sentido erigida desde la primera crisis del capitalismo en el siglo XIX; la primera crisis de la "razón industrializada".

Sin embargo, Bauman (2011) nos advierte sobre una situación peligrosa en relación con la modernidad y lo que ella implicó en el plano histórico y la manera en que desde ella se empezó a concebir el sufrimiento:

Una vez que se ha hechos pedazos la esperanza de constreñir la experiencia del Holocausto dentro de los límites del funcionamiento defectuoso (La modernidad incapaz de suprimir los factores de irracionalidad esencialmente ajenos, las presiones civilizatorias incapaces de dominar los impulsos violentos y emocionales y el fracaso de la socialización incapaz desde ese punto de crear el volumen necesario de motivaciones 
morales), nos podemos sentir tentados de enfilar la salida "evidente" del punto muerto teórico, que es proclamar que el Holocausto es un "paradigma" de la civilización moderna, su producto "natural" y "normal", quién sabe si también "corriente" y su "tendencia histórica". (p. 68)

De ahí la importancia del "método dialéctico" para esta reflexión, pues, de otro modo, el dato histórico por sí mismo, sin la fuerza de la crítica, elevaría a rango de verdad el hecho del Holocausto y, con esto, lo legitimaría porque no lo concebiría como una posibilidad que pudo ser evitada. De ahí que resulta improcedente y hasta incorrecto afirmar la expresión "el sufrimiento por Dios", porque es "el sufrimiento en Dios" la garantía de la esperanza, ${ }^{10}$ de que otra historia es posible y el compromiso con el futuro, porque, como afirma Metz, "el discurso sobre el Dios que sufre corre el peligro de restarle de antemano importancia teológica al sufrimiento humano. Si Dios sufre, entonces el sufrimiento -se dice- deja de ser una verdadera objeción contra Dios" (Metz, 2007, p. 33).

Por tanto, al hablar de la modernidad, ¿qué rostro le ha quedado a la historia?, y al hablar de Segunda Guerra Mundial, ¿qué rostro le ha quedado a Dios? Afirma Adorno (2008) un apotegma insoportable en el que dice que "después de Auschwitz ya no es posible hacer poesía". Surgiría, entonces, una pregunta aún más aterradora, ¿¿después de Auschiwitz es posible hacer teología? O bien, ¿̇es posible rezar después de Auschiwitz?, ¡es posible "hacer" historia después de las víctimas?

Con tales preguntas, se le exige a la teología, a la historia, una nueva apuesta epistemológica en su haber, una nueva forma de hacer, de ser, de convivir y de comprender. Auschwitz no puede convertirse en la privación e incapacidad de la experiencia histórica y la experiencia de la fe, pero sí en un giro radical y contundente en la historia de la fe, a saber: "los cristianos ya nunca podremos actuar como si Auschwitz no hubiera tenido lugar; pero superarlo es algo que, bien considerado, no somos capaces de hacer solos, sino solo conjuntamente con las víctimas de Auschwitz" (Metz, 2007, p. 50).

Memoria y conversión en realidad lo que quieren expresar es que la historia del sufrimiento debe ser asimilada desde la consciencia de la propia identidad y anunciarla con espíritu profético. Es el reconocimiento de la historia de la salvación capaz de transformar la memoria del creyente y del hombre en general, porque Auschewitz no es solo una referencia geográfica de una consciencia historicista, o de una historia idealizada, porque ningún creyente propiamente dicho, ningún capaz de sufrimiento, puede ya definir su propia identidad, ni la de una nación al margen de la historia del sufrimiento, al margen de la historia singular de Auschewitz.

10 Frente esto, la fundamentación teológica de Rahner (1998) puede resultar esclarecedora: “Dios ha de distinguirse como el absoluto y el infinito por excelencia. De otro modo sería objeto de conocimiento que comprende y no el fundamento del tal comprender. Él es esto y lo sigue siendo también allí donde es denominado y objetivado en una reflexión conceptual metafísica. En consecuencia, no puede necesitar de la realidad finita llamada 'mundo', pues de otro modo no se diferenciaría verdaderamente de él en manera radical, sino que sería una pieza de un todo superior, tal como es entendido en el panteísmo. Y, a la inversa, el mundo debe depender sin que por ello este llegue a depender de aquel, a la manera de como el señor depende de su siervo. El mundo no puede tener en sí nada que sea completamente independiente de Dios" (pp. 102-103). 
Teólogos e historiadores están llamados a la anamnesis (memoria) y a la metanoia (conversión), con lo cual muestran el desacuerdo con la actitud nihilista propia del hombre contemporáneo; nihilista, por un lado, y soberbio, por otro. Con todo,

el terror no expresado sobre el Holocausto que impregna nuestra memoria colectiva, relacionado con el deseo abrumador de no mirar el recuerdo de frente, es la sospecha corrosiva de que el Holocausto pudo haber sido algo más que una aberración, algo más que una desviación de la senda del progreso, algo más que un tumor canceroso en el cuerpo saludable de la sociedad civilizada; que, en resumen, el Holocausto no fue la antítesis de la civilización moderna y de todo lo que esta representa o, al menos, eso es lo que queremos creer. Sospechamos, aunque nos neguemos a admitirlo, que el Holocausto podría haber descubierto un rostro oculto de la sociedad moderna, un rostro distinto del que ya conocemos y admiramos. Y que los dos coexisten con toda comodidad unidos al mismo cuerpo. (Bauman, 2011, p. 77)

La memoria debe convertirse en el desafío de la realidad del presente; se hace imperativo arraigar, asumir y rebelarse contra el hechizo del olvido y de la amnesia. Sin Dios todo está permitido afirmó Dostoievsky; ${ }^{7}$ pues bien, hoy diríamos que sin Dios todo está olvidado: "Dios no puede ser pensado como trascendencia intemporal, pero tampoco como producto dramático de un ilimitado tiempo evolutivo, sino como final del tiempo que, viniendo a este, lo limita" (Metz, 2007, p. 52).

Por tanto, el diálogo entre historia y escatología es al mismo tiempo la consabida dialéctica entre objeto y sujeto, es decir, la esperanza nunca se diluye en la historia del sujeto que recuerda y espera. Solo cuando se reconoce que la historia está marcada por el recuerdo y la espera, entonces todas las luchas utópicas de los hombres adquieren profundo sentido y valor. ${ }^{11}$ Aunque desde la fe cristiana, esperanza no es lo mismo que utopía, cuando se asume la historia desde el recuerdo y la espera, se asume también que la utopía no es un tipo de fantasía en la que el sujeto se ve en la necesidad de idearse algo que aún no está y luego buscar la forma de realizarlo. La genuina experiencia del recuerdo y de la espera ubica al sujeto en la praxis en el mundo, y como sujeto cambiante, el cambio será condición sine qua non que cambia también la búsqueda utópica.

Al ubicar la fe en la historia, dentro de la memoria y confrontada por el futuro, esta ubicación ha de comprenderse al mismo tiempo desde la realidad eclesiológica que se sostiene en el espíritu anamnético del acontecimiento de Jesús de Nazartet, es decir, que se sostiene en la cristología. El gran reto de la Iglesia en el mundo posmoderno, hay que decirlo, es la evangelización de la compasión frente a la realidad del sufrimiento humano:

Todo sistema o paradigma de la iglesia no es algo estático, fijo en el pasado, sino que es algo vivo, dinamizado por el eschaton; pues el obrar de Dios, sus hechos en la historia, no son estáticos, estancados o cerrados, pues llevan siempre un elán escatológico, un dinamismo de futuro. Además, puede perderse la confianza en un determinado sistema doctrinal, pero la fe no descansa ahí, esta es en una persona que se llama Jesucristo. (Galeano, 2017, p. 407)

11 Es necesario considerar la diferencia entre la "espera” y la "demora”. Esta última, desde la perspectiva de la filosofía mesiánica de Ernst Bloch, deviene amarga apertura en tanto desvirtúa el presente y debilita la realidad (Moltmann, 1980). 
Una Iglesia compasiva orientada hacia la espera del Reino de Dios debe apostarle a un seguimiento creativo y expectante que se oponga a todo intento de privatización de la fe, porque Dios, como se sabe, no es propiedad privada de nadie, ni siquiera de la Iglesia. En su remembranza de Cristo y en su proclamación, es el topos donde se actualiza el Reino de Dios, ella no es lo último, pero en ella también se descubre lo último, lo que viene a ser liberado, y la compasión en ella es la praxis que se celebra y se realiza cuando se descubre la presencia de Dios en la historia de sufrimiento, porque "es en el desarrollo de la historia, en la obra de Dios en ella y en la respuesta humana, en la que surge la eclesiología" (Galeano, 2017, p. 414).

\section{Conclusiones}

A partir del Concilio Vaticano II vuelve a tomar importancia la verdad de los "signos de los tiempos" y, con ello, la reflexión del mundo contemporáneo inmersa en la pluralidad de la globalización, que exige un renovado discurso sobre Dios, un "nuevo hablar de Dios", ya no desde categorías abstractas ajenas al sufrimiento humano. Pero ¿qué se supone que quiere decir "signo"? ¿iA Acaso cuando se dice "de los tiempos" no constituye esto mucho más que un diálogo interpretativo con la historia, incluso mucho más que un cambio de concepción!?

El cristianismo ya no puede partir solo de nociones universales estrictas y dar la espalda a la singularidad del ser humano, singularidad real dada por el sufrimiento. Toda la cuestión de la teología y de su sentido se encuentra aquí, aunque sea todavía calladamente. En efecto, este sentido de la teología se resume en un interrogante fundamental: ¿̨cuándo, cómo y dónde nos es permitido hablar de Dios? De esta manera, la singularidad no puede ser sinónimo de lo particular porque el ser humano ha sufrido en su totalidad. Por tanto, el quehacer teológico está llamado a elevar a la humanidad de lo particular a lo universal. Sin embargo, esta universalidad no debe ser entendida como abstracción pura, lejana y cada vez más distante del hombre, sino como apertura y posibilidad que amplía el horizonte de sentido, si se me acepta el término fenomenológico, porque toda experiencia es irremplazable. En otras palabras:

Se me da la posibilidad de ampliar el horizonte, y si conocer y amar, como en la Biblia, en el fondo significan lo mismo, esa trayectoria me permitirá conocer mejor y tal vez también amar más a los demás. Si el distanciamiento de lo particular y la apertura a lo universal forman una experiencia singular, y ese doble proceso singulariza nuestras propias vidas a la vez que nos da acceso a la singularidad de los otros nos ofrece al mismo tiempo el medio de ampliar el pensamiento y de ponerlo en contacto con los momentos únicos, momentos de gracia irremplazables en tanto que singulares. (Ferry, 2007, p. 99)

Después de Auschwitz, la teología ya no puede abstraer, pero puede y debe encarnarse en la historia singular del hombre mismo en tanto sujeto sufriente. Los teólogos, como afirma Von Balthasar (2008), deben mirar más a los que aman, porque solo los que aman conocen a Dios, dado que "solo el amor es digno de fe".

En Jesucristo, el Logos ya no es el imperio de las ideas, los valores y las leyes que rige la historia y funda su sentido: Él mismo es historia. En la vida de Cristo, lo fáctico no solo coincide con lo normativo "de hecho", sino "necesariamente", porque el "hecho" es a la vez manifestación de Dios y prototipo humano de toda auténtica humanidad para Dios (Von Balthasar, 1992, p. 21). 
La crítica teológica de la Ilustración no ha de entenderse necesariamente desde un antagonismo o una antípoda cerrada, pues existen todavía consecuencias "ilustradas" a la espera de una interlocución teológica. Y, por otro lado, sería ingenuo no reconocer que la Ilustración y todas sus consecuencias han impregnado con su influjo la reflexión y la praxis de la teología actual.

El mismo fundamento y noción de subjetividad en la actual teología se debe a las consecuencias de la Ilustración en tanto concibe al hombre como sujeto autónomo y libre, aunque sea en abstracto. Y es esta abstracción lo que precisamente pretenden superar las teologías actuales; en todo caso, y como afirma Metz (1979), la teología tiene por tarea una "Ilustración de la Ilustración" (p. 45).

La noción de autenticidad erigida en la modernidad como consecuencia de la razón ilustrada, que devino secularización, la cual no solo ha de entenderse simplemente como la separación de la religión (¿Iglesia?) del ámbito privado y lejos del mundo civil, sino también como la crisis del hombre en tanto sujeto.

Es el "sujeto burgués" como portador de esta "nueva autonomía” el que se impone en todos los ámbitos de la sociedad y la cultura occidental. Un sujeto que replegado sobre sí mismo funda una "nueva religión privada", toda vez que descubre esta privatización en la división del trabajo. El sujeto burgués olvida rápidamente que "es un sujeto histórico como sujeto de la trascendencia, que está mediada históricamente su condición de sujeto, investido de una trascendentalidad ilimitada, de cara a su propio conocimiento por parte de él mismo, de cara a su libre realización" (Rahner, 1998, p.174).

Por consiguiente, la crisis del hombre ilustrado en el fondo es una crisis de una autosuficiencia en la manera en que este hombre burgués asume la historia y la fe: absolutizando y totalizando su subjetividad, y, con ello, desconociendo su lugar en la historia de la salvación. En efecto, "el hombre ni realiza su subjetividad trascendental de manera ahistórica en una experiencia meramente interna de una subjetividad que permanece igual, ni aprehende esta subjetividad trascendental por una reflexión o introspección ahistóricas posibles por igual en cada punto del tiempo" (Rahner, 1998, p. 174).

El diálogo entre historia y escatología encuentra su sentido no solo en un plano puramente categorial, sino que la historia ha de entenderse como narración, y escatología como recuerdo de la espera. El peligro de la pérdida de memoria implica no solo la cuestión del olvido sin más, y es que olvidar se traduce en la destrucción de la identidad y la obstrucción de la realización del sujeto, porque la "subjetivación histórica de un pueblo, raza o clase comienza siempre, de hecho, cuando se rompe el hechizo de la consciencia histórica "oficial", al desenmascararla como propaganda de los señores y los poderosos" (Metz, 1979, p. 83).

Por tanto, Auschwitz es el punto álgido de la singularización de las guerras del siglo pasado e incluso de las de nuestro tiempo, es la "empírica contingencia" que prohíbe todo intento de romanticismo teológico y toda comprensión soteriológica basada en una metafísica sin contexto y sin memoria. La estructura epistemológica de la teología, representante de las más altas nociones universales, debe verse, sentirse y realizarse en la interpelación radical del sufrimiento humano. Y, para lograr esto, la teología tiene que beber del recuerdo, esto es, de la historia, porque "la historia nos descubre sin cesar nuevas formas y propiedades de vida" (Moltmann, 1987, p. 86). 
La teología debe aprender a narrar o, al menos, recordarlo. Debe aprender a encontrar en su estructura lingüística las palabras más vivaces y veraces para expresar el sufrimiento y el horror que este produce, o, como diría Adorno (1975), "la necesidad de dejar que el sufrimiento hable con elocuencia es condición de toda verdad" (p. 27). El sufrimiento es el fundamento a priori a toda metafísica, después de todo, Cristo como "Alfa y Omega" es la promesa de Dios en el horizonte temporal.

Un horizonte limitado, definitivo y realizable que se opone a la noción de la experiencia de un tiempo infinito y estático. La singularidad de Dios en Jesucristo se mantiene en una dialéctica fundamental que supera el binomio especulativo de memoria y olvido, pues pensar al Dios de Abraham, Isaac y Jacob temporaliza toda lógica porque pensar a Dios es rememorarlo, añorarlo desde la fe que espera frente al sufrimiento y, sobre todo, frente al sufrimiento ajeno. En consecuencia, y tal como a afirma Metz (2007):

Se aboga por una metafísica negativa con un a priori de sufrimiento, de la que sirve para criticar asimismo un concepto moderno de razón que minusvalora el poder intelectual del recuerdo y estabiliza la amnesia cultural de nuestra sociedad todavía moderna o ya transmoderna. Tal amnesia cultural hace que la pregunta por el peligro de una posible repetición de Auschwitz no resulte en modo alguno obsoleta. (Metz, 2007, p. 63)

Saber esperar en la historia es saber comprender que necesitamos percatarnos del presente, del tiempo previo y del prometido. ${ }^{12}$ Comprender y creer que las cosas y los hechos pueden ser distintos de lo que son porque la fe transforma el "mundo objetivo" en "mundo vivido", y la esperanza transforma el "mundo de la existencia" en "mundo de la experiencia". Por tanto, esperar implica, entonces, asumir que las cosas no tienen que ser como actualmente se manifiestan; esperar es creer que las cosas pueden ser mejores de lo que son. Es la promesa de Dios a vivos y muertos, el clamor histórico de la libertad que puede seguir horrorizado por el pasado, pero nunca más dando la espalda al futuro.

\section{Referencias}

Adorno, T. (1974). Théorie esthétique. Klincksieck.

Adorno, T. (2008). Dialéctica negativa: La jerga de la autenticidad. Akal.

Agustín de Hipona. (2011). ¿Qué es el tiempo? Trotta.

Amengual, G. (1990). modernidad: Progreso o final de época. Caparrós.

Arendt, H. (1999). Eichmann en Jerusalen: Un estudio sobre la banalidad del mal (2.a ed.). Lumen.

Arendt, H. (2007). Responsabilidad y juicio. Paidós.

Arendt, H. (2008). De la historia a la acción. Paidós.

12 "La meta del hombre y de toda la creación no es otra cosa que la trinitización: el hombre está llamado a convertirse en lo que Dios es desde siempre, comunidad, intercambio de vida, para tener de una vez por todas la consumada communio del Dios trinitario. De ahí que lo mismo que la communio divina es en Dios ad intra y ad extra, tiene para el hombre una doble orientación: es comunidad con Dios y comunidad con los demás seres humanos y toda la creación" (Pérez, 2008, p. 363). 
Balthasar, H. U. von. (1962). Teología de la historia. Guadarrama.

Balthasar, H. U. von. (1968). La historia de la salvación antes de Cristo. Cristiandad.

Balthasar, H. U. von. (1971). Solo el amor en digno de fe. Sígueme.

Balthasar, H. U. von. (1978). El compromiso del cristiano en el mundo. Encuentro.

Balthasar, H. U. von. (1992). Teología de la historia. Encuentro.

Balthasar, H. U. von. (2008). Escatología en nuestro tiempo: Las cosas últimas del hombre y el cristianismo. Encuentro.

Bauman, Z. (1993). Postmodern ethics. Blackwell.

Bauman, Z. (2006a). La globalización: Consecuencias humanas. Fondo de Cultura Económica.

Bauman, Z. (2006b). modernidad líquida. Fondo de Cultura Económica.

Bauman, Z. (2011). modernidad y Holocausto. Sequitur.

Bauman, Z. y Tester, K. (2002). La ambivalencia de la modernidad y otras conversaciones. Paidós.

Benjamin, W. (2008). Tesis sobre la historia y otros fragmentos. Ítaca.

Bloch, M. (1965). Introducción a la historia. Fondo de Cultura Económica.

Bloch, M. (2001). Apología para la historia o el oficio de historiador (2.a ed.). Fondo de Cultura Económica.

Bloch, M. (2008). Historia e historiadores. Akal.

Boff, L. (2006). Virtudes para otro mundo posible. Sal Terrae.

Boff, L. (2017). La irrupción de espiritu en la evolución y en la historia. Trotta.

Burke, P. (1987). Sociología e historia. Alianza.

Burke, P. (1993). Formas de hacer historia. Alianza.

Burke, P. (2000). Formas de historia cultural. Alianza.

Correa Mazuera, A. (2011). Análisis de las posibilidades de la memoria histórica en la redención de las víctimas de la violencia en Colombia a partir de Walter Benjamin (tesis de maestría, Pontificia Universidad Javeriana). https:// repository.javeriana.edu.co/handle/10554/6229

Croce, B. (1960). La historia como hazaña de la libertad. Fondo de Cultura Económica.

Dostoievski, F. (2002). Los hermanos Karamazov. Juventud.

Ellacuría, I. (1973). Teología politica. Secretariado Social Interdiocesano.

Emerich, C. (2006). Dios en la historia del pensamiento filosófico. Sígueme.

Ferry, L. (2007). Vencer los miedos. Edaf.

Galeano Atehortúa, A. (2010). Visión cristiana de la historia: Ensayo de escatología. San Pablo.

Galeano Atehortúa, A. (2017). Una eclesiología histórica-escatológica para la posmodernidad. El cambio de paradigma dentro de la orientación postmoderna hacia la historia y la hermenéutica. Cuestiones Teológicas, 44(102), $397-$ 421. https://doi.org/10.18566/cueteo.v44n102.a08 
Gallegos, A. (2003). Acordarse de los pobres: Textos esenciales de Gustavo Gutiérrez. Fondo del Congreso del Perú.

González Faus, J. I. (2008). El rostro humano de Dios de la revelación de Jesús a la divinidad de Jesús. Sal Terrae.

Fraijó Nieto, M. (1994). Filosofía de la religión: Estudios y textos. Trotta.

Gutiérrez, G. (2004a). Teología de la liberación: Perspectivas (17.a ed.). Sígueme.

Gutiérrez, G. (2004b). Testigos de la memoria de Dios. Selecciones de Teología, 43(169), 13-15. https:// seleccionesdeteologia.net/selecciones/llib/vol43/169/169_gutierrez.pdf

Haldane, J. (1951). Everything has a history. Cambridge University Press.

Kant, I. (2004). ¿Qué es la Ilustración? Alianza.

Kasper, W. (1974). Fe e historia. Sígueme.

Kasper, W. (2013). El Dios de Jesucristo. Sal Terrae.

Kierkegaard, S. (2001). Temor y temblor (4..$^{\mathrm{a}}$ ed.). Tecnos.

Lévinas, E. (1977). Totalidad e infinito: Ensayo sobre la exterioridad. Sígueme.

Lévinas, E. (1993). El tiempo y el otro. Paidós.

Lévinas, E. (1997). Fuera del sujeto. Caparrós.

Lévinas, E. (2006). Los imprevistos de la historia. Sígueme.

López López, E. A. (2013). Perdonar sí, olvidar no una aproximación a la reconciliación en Colombia desde los sentimientos morales. Universitas Philosophica, 30(61), 85-96. https://revistas.javeriana.edu.co/index.php/ vniphilosophica/article/view/10634

Metz, J. B. (1979). La fe en la historia y la sociedad: Esbozo de una teología política fundamental para nuestro tiempo. Cristiandad.

Metz, J. B. (2001). Hacia una cristología después de Auschwitz. Selecciones de Teología, 158, 111-116. https:// seleccionesdeteologia.net/selecciones/lib/vol40/158/158_metz.pdf

Metz, J. B. (2002a). Dios y el tiempo teología y metafísica en las fronteras de la modernidad. Selecciones de Teología, 171. https://seleccionesdeteologia.net/selecciones/lib/vol41/162/162_baptist.pdf

Metz, J. B. (2002b). Dios y tiempo: Nueva teología política. Trotta.

Metz, J. B. (2007). Memoria passionis: Una evocación provocadora en una sociedad pluralista. Sal Terrae.

Metz, J. B. (2013). Por una mistica de ojos abiertos: Cuando irrumpe la espiritualidad. Herder. https://doi.org/10.2307/j. ctvt $7 \times 5$ w 4

Moltmann, J. (1972). Teología de la esperanza. Sígueme.

Moltmann, J. (1980). Utopia y esperanza: Diálogo con Ernst Bloch. Sígueme.

Moltmann, J. (1987). Teología politica ética politica. Sígueme.

Moltmann, J. (1992a). La justicia crea futuro: Política de paz y ética de la creación en un mundo amenazado. Sal Terrae. 
Moltmann, J. (1992b). Teología política y teología de la liberación. Carthaginensia, 8(13-14), 489-501. https://www. revistacarthaginensia.infoestima.com/index.php/CARTHAGINENSIA/article/view/297

Moltmann, J. (2006). La teología ante el proyecto escatológico de la modernidad. Selecciones de Teología, 144, 255264. https://seleccionesdeteologia.net/selecciones/lib/vol36/144/144_moltmann.pdf

Moltmann, J. (2015). ¿Hay esperanza para la creación amenazada? Sal Terrae.

Müller, G. (2014). Iglesia pobre y para los pobres. San Pablo.

Pablo, Obispo. Vaticano II. Gaudium et spes. Diciembre 7 de 1965. https://www.vatican.va/archive/hist_councils/ ii_vatican_council/documents/vat-ii_const_19651207_gaudium-et-spes_sp.html

Pérez Prieto, V. (2008). Dios, hombre, mundo: La trinidad en Raimon Panikkar. Herder.

Rahner, K. (1965). El problema de la hominización: Sobre el origen biológico del hombre. Cristiandad.

Ricoeur, P. (1995). Teoría de la interpretación: Discurso y excedente de sentido. Siglo XXI.

Rahner, K. (1998). Curso fundamental sobre la fe: Introducción al concepto de cristianismo. Heder.

Ricoeur, P. (1999). Historia y narrativa. Paidós.

Ricoeur, P. (2008). Vivo hasta la muerte, seguido de Fragmentos. Fondo de Cultura Económica.

Ricoeur, P. (2010). La memoria, la historia, el olvido (2. a ed.). Trotta.

Ricoeur, P. (2015). Historia y verdad. Fondo de Cultura Económica.

Torres, A. (2005). Esperanza a pesar del mal: La resurrección como horizonte. Sal Terrae.

Walls, J. (2008). The Oxford handbook of eschatology. Oxford University Press. https://doi.org/10.1093/ oxfordhb/9780195170498.001.0001

Weber, M. (1985). La ética protestante y el espiritu del capitalismo. Orbis.

Weber, M. (2009). La ciencia como profesión. Biblioteca Nueva.

Winner, L. (1987). La ballena y el reactor. Gedisa.

Wittgenstein, L. (2016). Tratado lógico-filosófico. Tecnos.

Zamora. J. (2008). El perdón y su dimensión política. Anthropos. 